\title{
Improving geological and process model integration through TIN to 3D grid conversion
}

Carl Watson, Jennifer Richardson, Ben Wood, Christopher Jackson and Andrew Hughes

British Geological Survey, Keyworth, Nottingham NG12 5GG, UK

Corresponding author - Carl Watson: carl.watson@bgs.ac.uk

\begin{abstract}
The ability to extract properties from 3D geological framework models for use in the construction of conceptual and mathematical models is seen as increasingly important, however, tools and techniques are needed to support such information flows. Developing such methodologies will maximize the opportunity for information use and re-use, this is particularly important as the true value of such assets is not always known when they are first acquired. This paper briefly describes the cultural and technical challenges associated with the application of information derived from $3 \mathrm{D}$ geological framework models by hydrogeological process models. We examine how these issues are being addressed and present a tool, SurfGrid, which allows a user to generate 3D grids (voxels) of parameterized data from a series of geological surfaces.

The procedures and tools described offer the ability to re-use expensively created assets by providing user friendly techniques that enable multidisciplinary scientists to extrapolate property distributions from geological models.
\end{abstract}

\section{Keywords}

Geological knowledge transfer, Grid conversion, Integrated Environmental Modeling, 3D geology 


\section{Introduction}

Geological survey organizations (GSOs) have responsibilities to: undertake geological surveys, conduct research supporting development of subsurface resources, and provide advice to policy makers on environmental issues and natural hazards. Advances in computing technology have resulted in GSOs becoming increasingly digital; paper maps have given way to Geographical Information Systems (GIS) and specialist 3D software has been developed to enable the creation of 3D geological framework models. GSOs now develop and maintain most of the 3D geological framework models developed beyond the commercial world of hydro-carbon exploration. GSOs are increasingly involved in answering questions about complex environmental processes. These questions require combined knowledge and data from a wide range of disciplines. This often requires combining models from different disciplines to solve complex environmental problems; a topic defined as "Integrated Environmental Modeling (IEM)" (Laniak et al., 2013; Moore et al., 2012). Frequently there is a lack of integration between 3D geological framework models and process models such as hydrogeological (groundwater) models. However, geological information provides valuable guidance to the conceptualization of direct and indirect influences on the surface and subsurface properties and processes being investigated by the process model.

In most GSOs 3D geological framework models are created in a deterministic manner employing implicit geological knowledge from their geologists, often by defining a series of lithostratigraphic surfaces. However, in some cases, 3D geological property models are created with property distributions produced through stochastic methods. TNO - The Geological Survey of the Netherlands has extensively employed such methods at regional and national scales, especially for models of the shallow subsurface (van der Meulen, 2013). A multitude of methodologies can be employed to generate 3D geological framework models and these are summarized by Berg et al (2011). This paper focuses on the transfer of information from lithostratigraphic 3D geological framework models created with expert implicit geological knowledge. The transfer of 3D property grids is documented elsewhere (e.g. Fogg et al., 2000; Turner et al., in press; Labourdette et al., 2008). While some potential users will want to transfer or generate in-layer property variations through stochastic methods, this paper does not address this requirement.

The lack of integration between geological models and process models is not simply down to a lack of technical solutions, there are cultural challenges which result from differing priorities and scales of interest. In the case of groundwater process models, it is clear that surface and subsurface hydrological processes are influenced by geological structures. Locations of permeable and impermeable units control groundwater flow paths; faults may act as conduits or barriers to flow. However, in many situations a groundwater model is created with little or no reference to a related 3D geological framework model. Even when a groundwater model is informed by a 3D geological framework model, a series of manual data conversions are often required prior to the information 
being utilized. This introduces the possibility of user error. The lack of a direct link between the two models precludes the automatic propagation of any change in the geological model to the groundwater model. There are two main reasons why 3D geological framework models are infrequently used to define groundwater models.

First, most 3D geological framework models are delineated on the basis of lithostratigraphy and structures at the formation level. The complexity contained in the 3D geological framework model is often replicated in the hydrogeological conceptual model. However, practical considerations of computational speed and efficiency, and responses to the purposes and goals of the groundwater investigation, result in considerable simplifications when the groundwater flow model is created. Secondly, a generic grid export from typical 3D geological framework models that is amenable to commonly used numerical groundwater modeling packages has not been available. Some existing commercial software partially address the problem of data transfer from 3D geological framework models to process models. The hydrocarbon exploration and production community often transfers seismic data into 3D geological framework models such as Petrel (Schlumberger, 2014); these then influence the creation of appropriate process models supporting hydro-carbon exploration. The RESQML $^{\text {TM }}$ data exchange standard (King et al., 2012) is under active development to support these data transfers. Some groundwater investigation software includes functionality to create 3D hydraulic property grids that are representative of and derived from modeled geological units. Examples include: Visual MODFLOW 3D-Builder, an add-on module for the Visual MODFLOW software; a solution to convert properties in GOCAD geological models into grid formats used by the Groundwater Modeling System (Ross et al., 2005); and GOFEFLOW (Smirnoff et al., 2011) generates FEFLOW compliant data from GOCAD modeled surfaces. Whilst these solutions appear to address the conceptual issue of transferring geologically controlled properties to process models, they are designed to work with specific software packages and are focused on the needs of defined applications.

There remains a need for a generic solution that supports the creation of 3D gridded subsurface property representations derived from 3D geological framework models. The solution should be flexible enough to appeal to all user communities that could benefit from gridded subsurface property data derived from 3D geological framework models, including groundwater modeling, geotechnical engineering studies and 3D data visualization. This approach assumes that lithostratigraphically constrained 3D geological framework models are a suitable basis for assigning representative property values to geological units which could be used to inform process models. Where this is not the case, alternative solutions should be considered.

This paper describes a solution incorporating an information workflow and software tool, SurfGrid, developed by the British Geological Survey (BGS) to support the transfer of volumetric property data from 3D geological framework models, created using GSI3D (Kessler et al., 2009; Kessler \& Mathers 2006) and GOCAD® (Berlioux, 1994), into open grid-based formats that can be used within a range 
of visualization and process modeling software. SurfGrid outputs were designed with certain software in mind, ArcGIS ${ }^{\mathrm{TM}}$ (Ormsby et al., 2010) to view, analyze and edit spatial data, GeoVisionary (Napier, 2011) to view extensive datasets from multiple sources and the process modeling software tools: MODFLOW (Barlow \& Harbaugh, 2006), FEFLOW (Trefry \& Muffels, 2007), and the BGS ZOOM family of groundwater models, ZOOMQ3D (Jackson \& Spink, 2004), ZOODRM (Hughes et al., 2008, Mansour et al., 2008) and ZOOPT (Jackson, 2004). Finally, we will look at the challenges that remain, and briefly consider the medium to longer-term goals of this approach.

\section{An Example of Linking Geological and Process Models}

Over many years, the BGS has created numerous 3D geological framework models at various scales and resolutions within the Thames basin, south-east England to address a variety of questions raised by clients (e.g. Mathers et al., 2014; Aldiss et al., 2012; Royse, 2010; Royse et al., 2009). The lithostratigraphic units in these models have focused on superficial deposits, whilst aquifers, such as the underlying Chalk, appear as large homogenous units. This contrasts with the desire to study subdivided heterogeneous layers for subsurface fluid flow investigations.

Considerable attention has been paid to groundwater resources in this area. According to Whiteman et al. (2012), there have been no less than 14 groundwater resource models developed for the Thames catchment by the Environment Agency. Some of these BGS groundwater modeling efforts contain elements of model integration (Hughes et al., 2011). There has been a tendency in the recent past to use a simplified form of the geology within mathematical process models, but there is a growing need to honor geological complexity such as faulting or discontinuous units (Blessent et al., 2009;

Manzocchi et al., 2010; Kessler et al., 2009).

Recognizing the need to develop technologies and standards to enable scientists to solve increasingly complex environmental questions (Laniak et al., 2013; Giles et al., 2010), the BGS undertook a study of the water resources in the Thames catchment using a series of linked models (Mackay et al., 2013). A series of interdependent model components were developed and subsequently linked using an IEM standard called OpenMI (OpenMI Association, 2010; Mansour et al. 2013).

The right side of Figure 1 shows how a linked series of hydrologic process models defined conditions within the Thames basin. These included a Muskingum-Cunge river flow routing model, MCRouter, and two groundwater models - a distributed ZOOMQ3D model of the Chalk and a semi-distributed model of the Limestone. These were linked by a river flow model (Mansour et al., 2013). Recharge was modeled by a distributed ZOODRM groundwater recharge model (Hughes et al., 2008). These recharge and groundwater flow models reflected the geologic conditions represented by a number of geological models of the Thames region, but shown schematically as a single 3D model on the left of Figure 1. However, there was no systemized, automated procedure to transfer information between the geological models and the process models. As shown in Figure 1, geological properties 
information was transferred manually between the 3D geological framework models and components within the OpenMI coupled hydrologic models of the Thames catchment.

In fact, information on geological structure and properties was not explicitly derived from the 3D geological framework models, but was effectively embedded within the ZOODRM and ZOOMQ3D recharge and groundwater flow model components. This reflected the limitations of the OpenMI interface and the original concepts of these models which were designed to incorporate spatial hydrological and hydrogeological data.

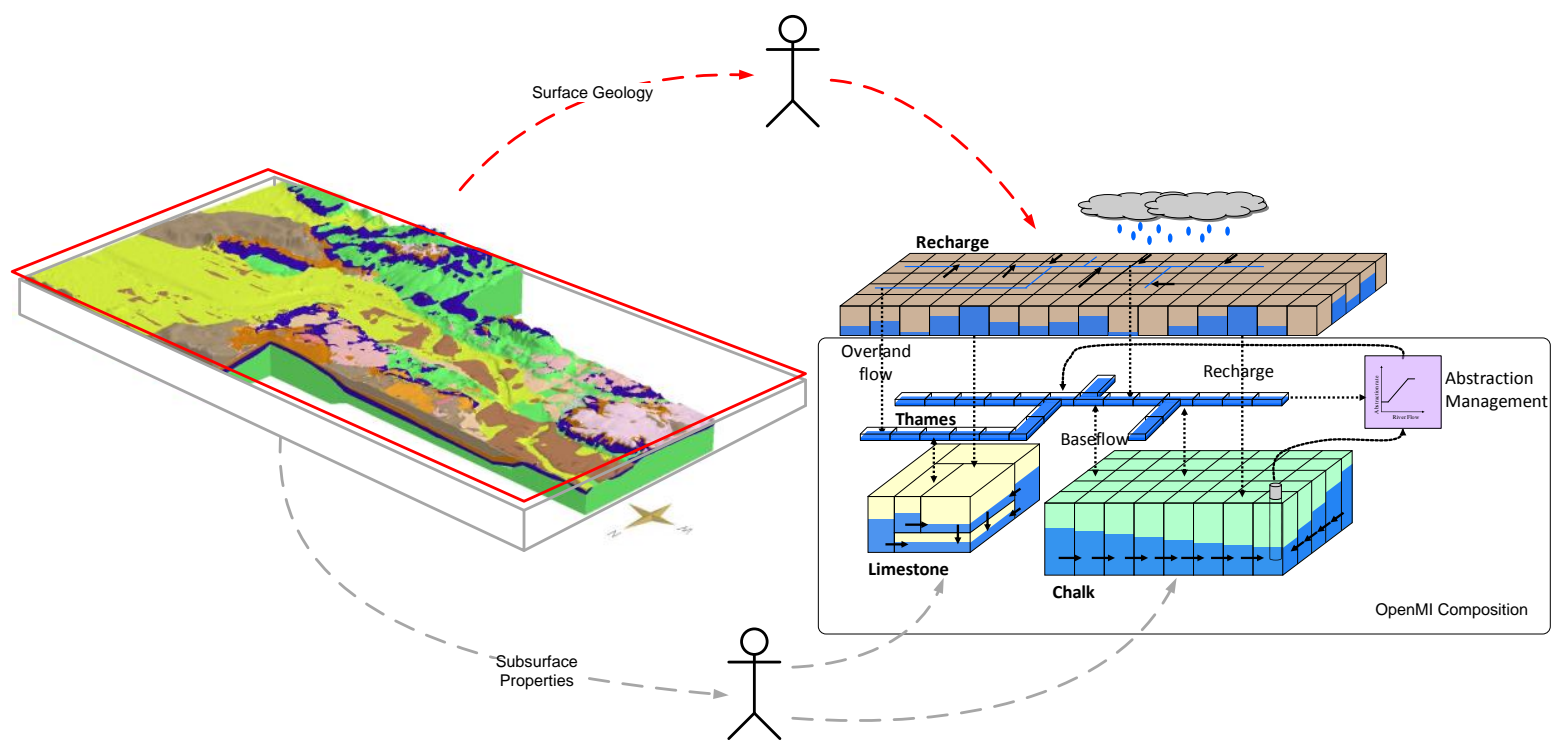

Figure 1: Thames catchment example of the manual transfer of surface and subsurface properties between 3D geological models (left) and process model components within an OpenMI coupled composition (right).

\section{Additional Concerns Influencing Model Linkages}

To understand how a GSO could provide linked time-varying models, in 2010 the BGS undertook a scoping study called DREAM (Giles et al., 2010). The scoping study identified several reasons constraining the application of existing (legacy) 3D geological framework models to process modeling investigations:

- The geographical areas rarely coincide. For example, groundwater processes tend to be modeled on a catchment-wide scale whereas geological models often cover smaller areas.

- The hydraulic properties of an area are often defined by lithological features such as weathering zones and the presence or absence of flow paths. These features are traditionally absent from 3D geological models.

- Geological models typically represent larger faults, but faults with relatively minor throws may be considered structurally insignificant by a geologist and, therefore, will be absent from the model. However, these faults may significantly influence fluid flow. 
- The spatial data formats used by the GSO geological framework modeling community tend to involve the creation of 3D triangular irregular networks (TINs) (Berg et al., 2009) whilst it is common for mathematical process models to operate on regular or semi-regular grid formats.

\section{Methodology Governing Development of SurfGrid}

Given the range of cultural and technical issues described in Sections 2 and 3, the primary objectives governing the development of SurfGrid were to:

- Improve communication between geologists and process modelers through improved workflows and easy to use software.

- Develop software to produce property data from 3D geological models. Exports should be clearly described and compatible with a range of process models, data manipulation tools and visualization software.

To facilitate the flow of information from geological to process models, a two part solution was developed that involved: 1) a simple workflow procedure describing how the information would transfer from geological model to process model, and 2) development of a software tool, called SurfGrid, to generate the gridded output files. These were supported by documentation to encourage and guide users. As the development of SurfGrid progressed, our understanding of the issues grew and future challenges were identified, which are described in Section 6.

\subsection{The Workflow Procedure}

A simple four step procedure was developed (Figure 2) to produce volumetric property data from a geological model:

1) create the $3 \mathrm{D}$ geological model

2) define mapping between stratigraphic units and properties to be exported

3) specify the geographic extent, mesh size and properties to be exported

4) select the file format to be generated.

Once generic grid files have been generated by SurfGrid, they can either be used directly by the process model software or, if necessary, some additional data manipulation may be performed prior to their use. 


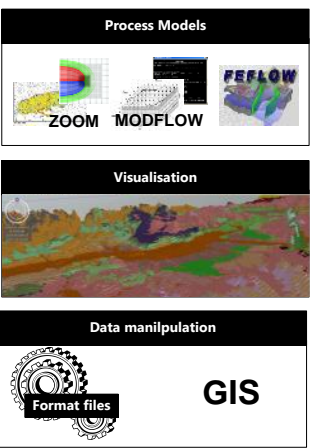

Figure 2: Four step procedure for generation of subsurface volumetric property data

\subsubsection{STEP 1: Create 3D geological model}

If no geological model exists for the area of interest, a new geological model can be tailor-made for the area at the level-of-detail required in a process model. However, if a geological model covering at least part of the area already exists, a new version of an existing model can be created at a significantly lower cost. In order to maximize the opportunity for this efficient re-use of geological models by process models, it is desirable for GSOs to develop 3D geological framework models that cover larger areas, such as the catchment areas used in subsurface flow modeling. If such a 3D geological framework model is too complex for the application, units can be amalgamated and faults removed. New stratigraphic surfaces and faults may be added when more detail is required.

GOCAD and GSI3D were the two geological modeling packages considered during the development of SurfGrid. GSI3D was the primary focus for the development team due to experience with the code base and through its inbuilt support for the GOCAD triangulated surface format, TSurf (Berlioux, 1994). With this capability, importation of GOCAD geological models into GSI3D and then generation of 3D grids becomes a straightforward process.

\subsubsection{STEP 2: Assign properties to geological units}

The relationships between stratigraphy and the physical properties, required by a target process model, need to be considered. By examination of the geological model created in step 1, it should be possible to relate one or more properties to each stratigraphic unit. Each property is assigned a quantitative or qualitative value. In effect, the user bulk-attributes each stratigraphic volume with values for one or more properties. Thus, the spaces between the modeled geological stratigraphic surfaces are assigned uniform values for each property. Multiple stratigraphic units may be assigned the same property value, or individual units may have distinctive values.

\subsubsection{STEP 3: Specify geographical extent, mesh size and properties to be exported}

Where the exported property is destined for use in a mathematical process model it is important to generate a grid which is compatible in spatial extent and mesh size to that required in the target model. Therefore, rather than simply exporting all properties for the entire volume of the geological 
model, the user should be able to define the export parameters, such as the area of interest, desired grid size and properties to be exported.

\subsubsection{STEP 4: Select file format and refine output content}

3D grid file formats should be compatible with commonly-used process models. These formats should be clearly documented to maximize usage and highlight any known limitations.

\subsection{SurfGrid: A Tool to Convert Geological Surfaces to 3D Properties Grids}

The procedure outlined in Section 4.1 has been implemented in new software, called SurfGrid. It was developed using the Java programming language and deployed as a plug-in for GSI3D. Although GSI3D is proprietary software, it can accept models using GOCAD TSurfs and TINs created from raster data. There are plans for a more generic SurfGrid tool that is freely available and will produce grids from a variety of sources.

A cross-section based geological model is created (using GSI3D) and the stratigraphic sequence of geological units is defined in an ASCII text file called the Generalized Vertical Section (GVS). The GVS contains a unique ID for each unit and details such as a name, lithology and geological age. By adding additional columns to the GVS, relationships between each stratigraphic unit and one or more properties are established. It is possible to generate SurfGrid exports containing only lithostratigraphic values and subsequently assign new properties to grid cells, however, where the relationships between geological unit and representative property values can be identified prior to grid generation the GVS remains the most efficient way for bulk attribution of export grids. Thus, Steps 1 and 2 of the procedure outlined in Section 4.1 are achieved by entering values for each property for each unit in the GVS. Figure 3 shows a conceptual example of stratigraphy being mapped against two new properties $\mathrm{P} 1$ and $\mathrm{P} 2$. 


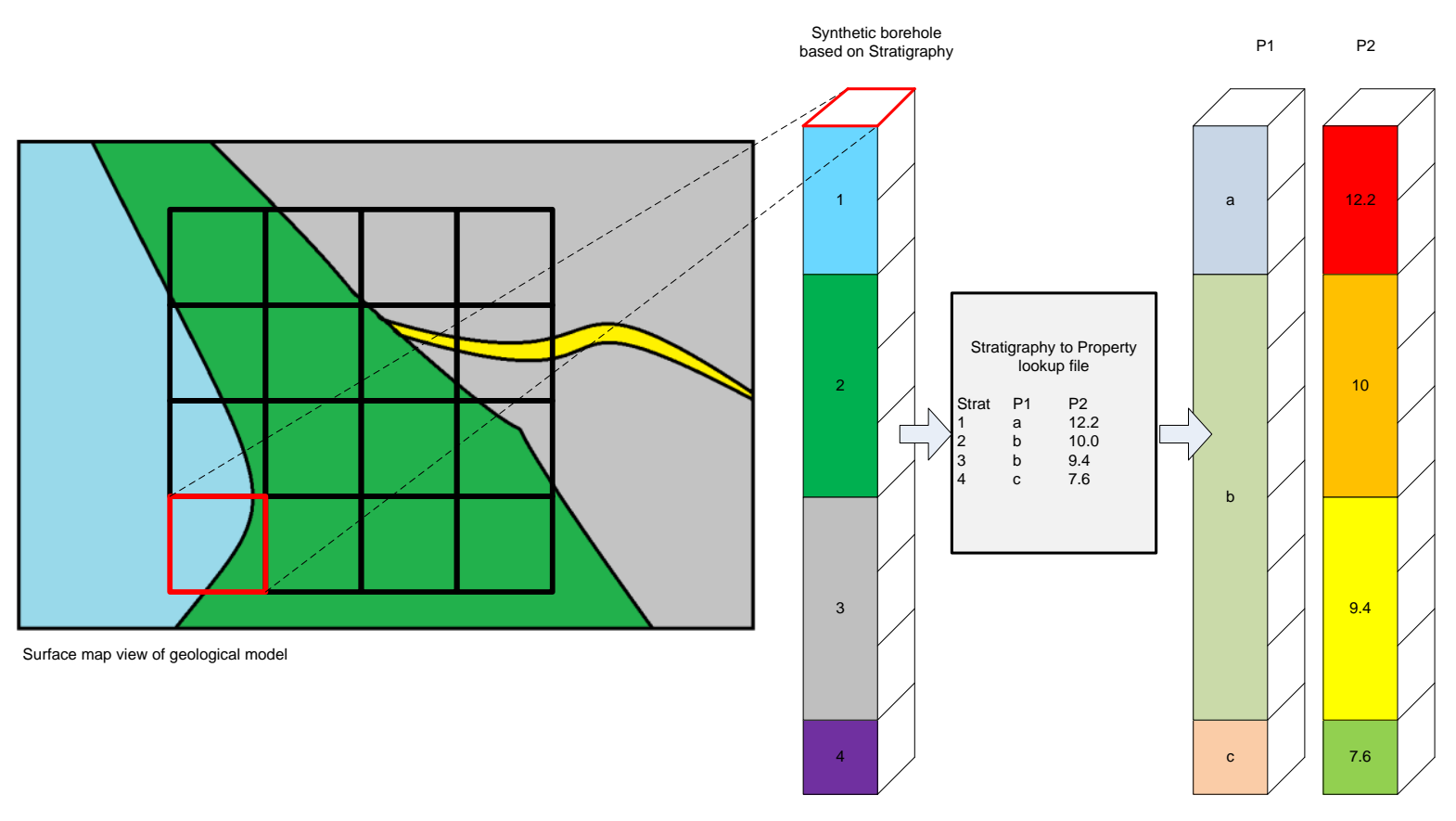

Figure 3: Synthetic boreholes created for each cell in 2D grid of selected area

The SurfGrid tool contains a simple form that allows a user to define the area of interest, the number of cells in each direction, cell dimensions and select which properties should be exported, Figure 4. 


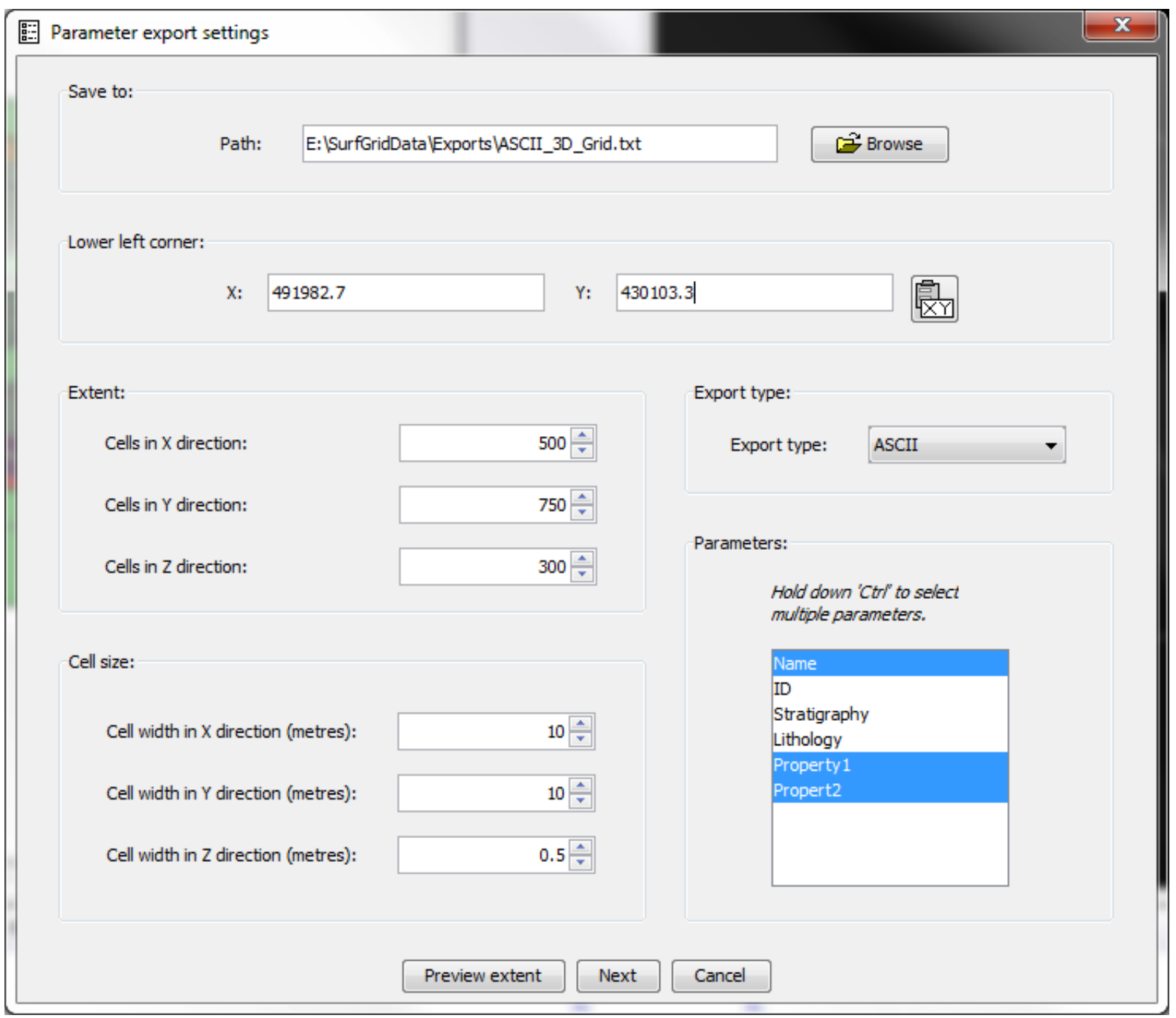

Figure 4: The SurfGrid export form. Users manually type in enter Lower left corner coordinates or select from a point in the map window

The Preview Extent feature overlays the user defined grid in the GSI3D map window as shown in Figure 5. Step 4 simply involves the selection of an export format from a drop down list and now the SurfGrid tool has all the information necessary to generate the specified outputs. 


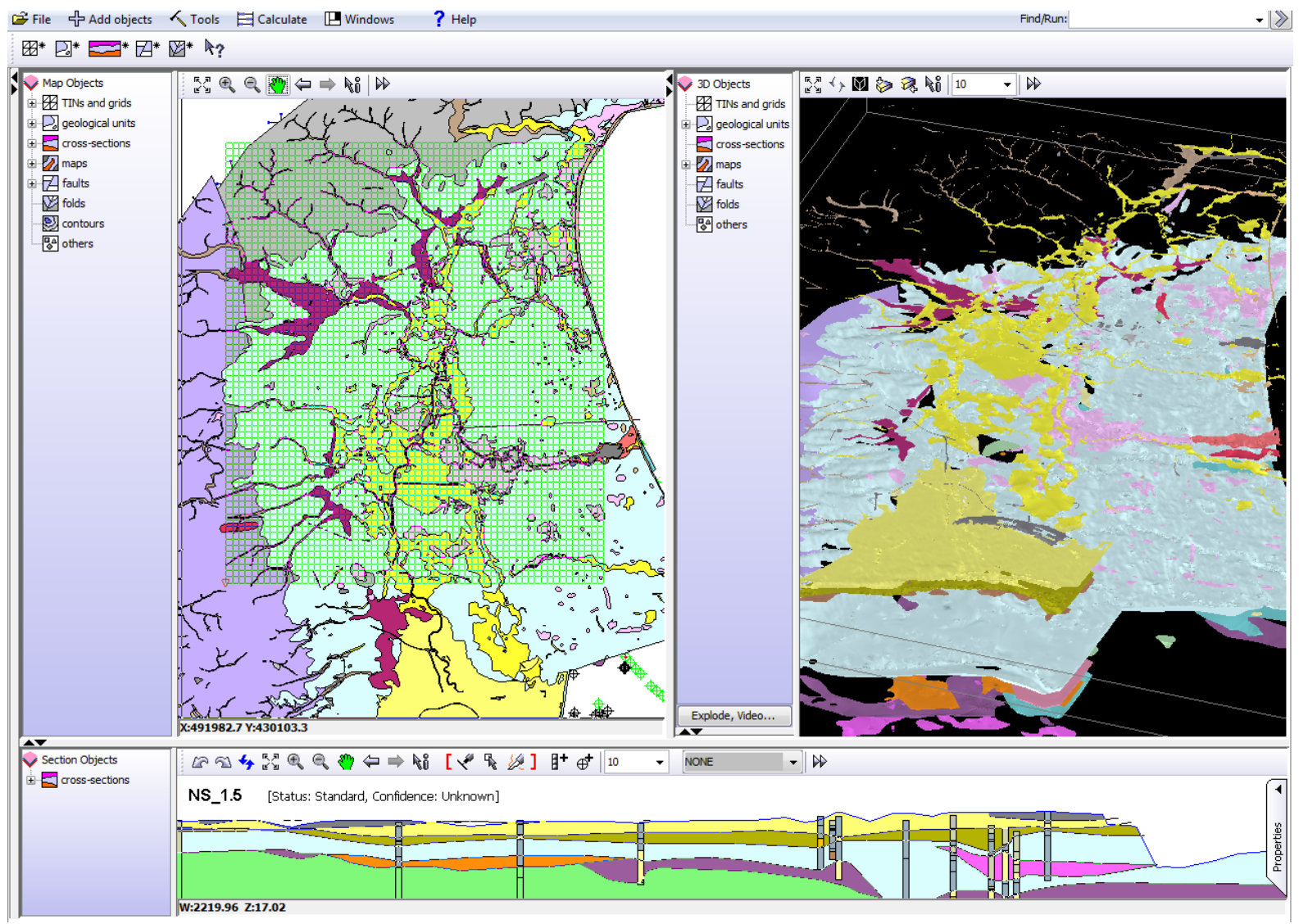

Figure 5: The GSI3D user interface showing map window, top left, cross section window across the base and 3D window on the right. The map window shows a user defined grid from SurfGrid tool overlying the area of interest.

\subsubsection{SurfGrid logic}

The SurfGrid tool starts the export generation process by defining, in memory, a 2D horizontal $(\mathrm{x}, \mathrm{y})$ grid using the specified grid coordinates and mesh size (Figure 4). Starting with the lower left corner of the $2 \mathrm{D}$ grid, a synthetic borehole is created for each cell. It contains stratigraphic properties and model horizon elevation values, as shown in Figure 3. By mapping the stratigraphy to each property, as defined in the GVS file, additional synthetic boreholes are added to memory and combined to produce a 3D grid of cells, each containing one or more property values.

Assigning a property to a 3D cell that falls wholly within a single stratigraphic unit is simple enough. However, potentially complex logic is required to decide which value to assign to a cell split by one or more stratigraphic surfaces. A relatively simple strategy was selected. It identifies the stratigraphy present at the centre point of each 3D cell. There are issues associated with this approach which need to be clearly communicated to the users, such as an over simplification of the structure; thin units can completely disappear whilst others appear to gain significance. Figure 6 shows a simplified 2D example of these issues, most of these can be mitigated by selecting a finer mesh size. Alternative approaches include checking which stratigraphy occupied the largest percentage of each cell or capturing the percentage of each stratigraphy within a cell and computing weighted-average values for associated properties. 

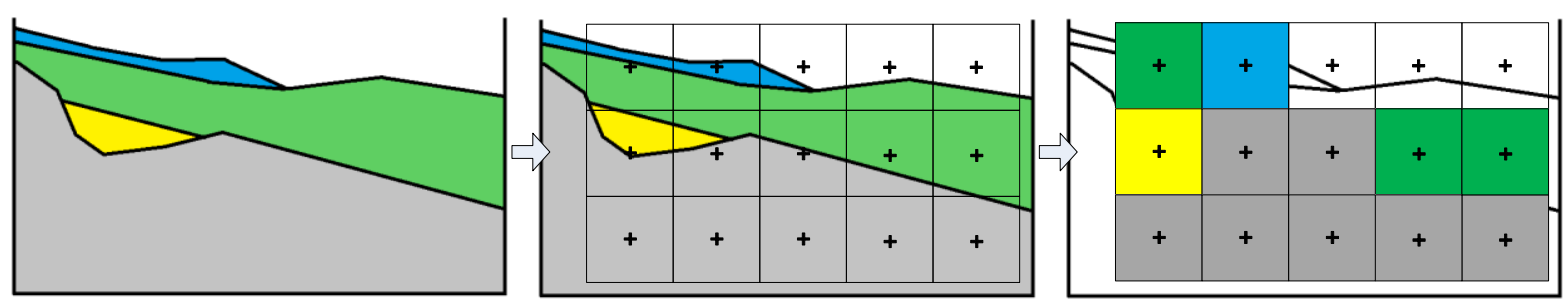

Figure 6: Assignment of 3D cell property based on which stratigraphy is present at each centre point (small cross)

\section{Results}

SurfGrid produces 3D gridded data in three digital file formats. The logic that converts geological surfaces into gridded structures is independent of the export functionality therefore new formats can be added as required. The three formats described in this section are human readable, open formats which have been selected for use within targeted software such as MODFLOW and ZOOMQ3D for groundwater modeling, ArcGIS for data manipulation, and GeoVisionary for visualization. These files provide a means for transferring geological structural data from TIN based geological models to software which requires subsurface properties in gridded formats. To date the $3 \mathrm{D}$ gridded outputs have been manually loaded into target software but the development of automated loaders should lead to closer integration, more rapid and regular exchanges of data and perhaps two way transfers of data.

\subsection{The output formats}

\subsubsection{CSV ASCII 3D grid format}

This 3D grid format is based upon the ESRI 2D grid format (McRae \& Shah, 2009) and adapted by TNO to provide a standard for voxelated data in geological models within the Netherlands (Stafleu et al., 2013). It is a human readable format that handles gridded multi-property data in a relatively efficient manner. Regular grids do not require the coordinates for each cell to be captured. Instead the file comprises a brief header defining the grid type, cell order, grid dimensions and properties. Following the header is a block of data equating to the property values for each cell. 


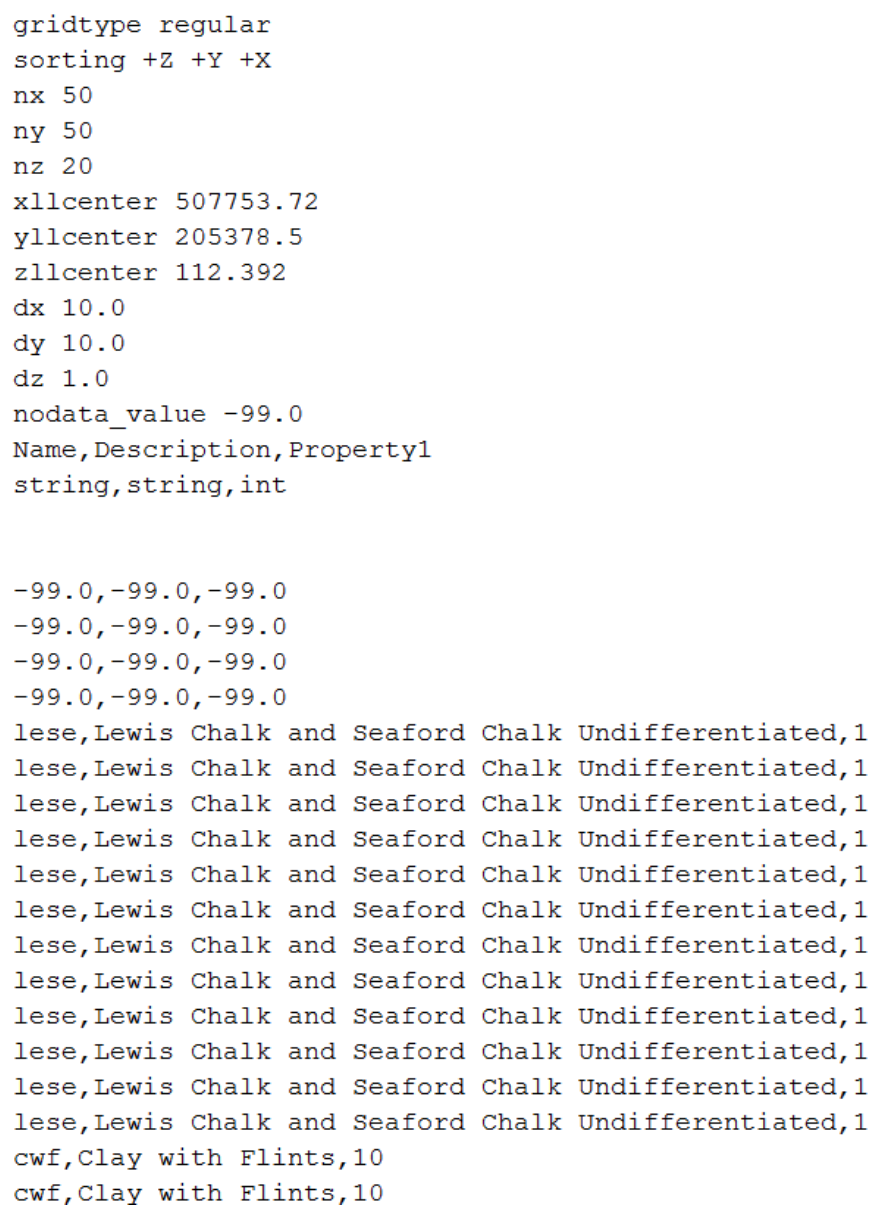

Figure 7: ASCII 3D Grid example, containing nodata_value representing cells outside the modeled area

\subsubsection{BlockModel format}

This format is based upon the block model file formats used in the Vulcan geological modeling software (Maptek, 2013). It has been incorporated into SurfGrid for two reasons. Firstly, this format is supported by the visualization software GeoVisionary, and thus provides a rich visualization option for display and analysis of multi-property volumetric data. Secondly, the BlockModel format defines the coordinates of the cell center point and dimensions, which provides a potential stepping stone towards the generation of semi-regular grids (Fig. 9). Using GeoVisionary has shown that geological models of varying size and complexity have been successfully exported in this format. The entire Thames basin model was successfully converted to the BlockModel format using a cell size of $250 \mathrm{~m}$ by $250 \mathrm{~m}$ by $2 \mathrm{~m}$ for an area approximately 115 by 35 kilometers, resulting in approximately 16,000,000 cells (Figure 8). 


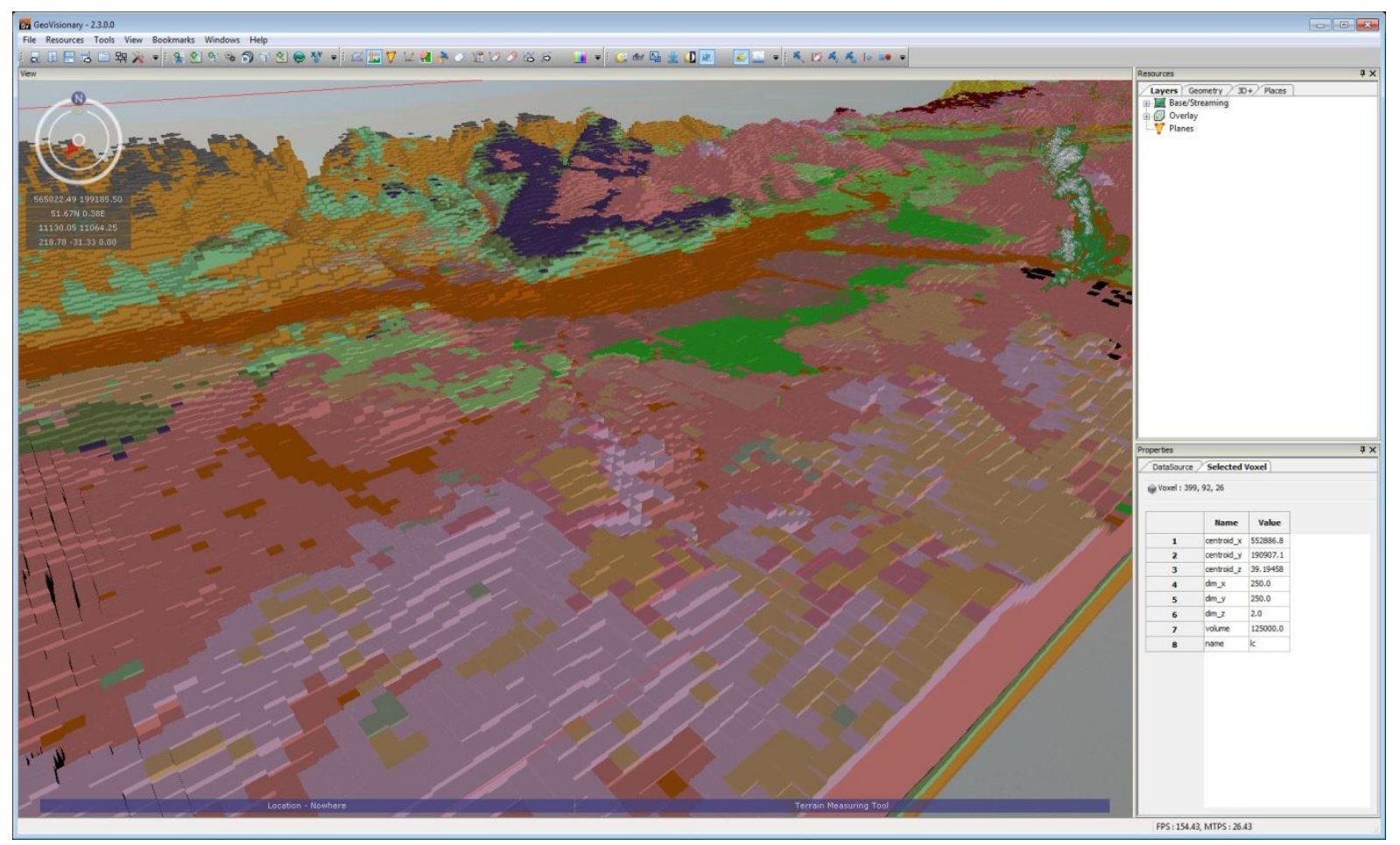

Figure 8: Thames Basin model in GeoVisionary software using BlockModel export file format

\begin{tabular}{|c|c|c|c|c|c|c|c|c|c|}
\hline $\begin{array}{l}\text { centroid_x, } \\
\text { Variable descriptions:, }\end{array}$ & centroid_y, & centroid_z, & dim_x, & dim_y, & dim_z, & volume, & name, & Permeability, & GW_Layer \\
\hline Variable types:, & , & , & , & , & , & , & string, & string, & int \\
\hline Variable defaults, & , & , & , & , & , & , & , & 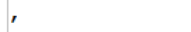 & \\
\hline 502990.2 & 444284.22 , & -47.2426 & 100.0, & 100.0, & 10.0, & 100000.0, & CHLK, & $\mathrm{HIGH}$, & 2 \\
\hline 502990.2, & 444284.22 , & -37.2426, & 100.0, & 100.0, & 10.0, & 100000.0, & CHLK, & $\mathrm{HIGH}$, & 2 \\
\hline 502990.2, & 444284.22 , & -27.2426, & 100.0, & 100.0, & 10.0, & 100000.0, & CHLK, & $\mathrm{HIGH}$, & 2 \\
\hline 502990.2, & 444284.22, & -17.2426, & 100.0, & 100.0, & 10.0, & 100000.0, & CHLK, & $\mathrm{HIGH}$, & 2 \\
\hline 502990.2, & 444284.22 , & -7.2425995, & 100.0, & 100.0， & 10.0, & 100000.0, & CHLK, & $\mathrm{HIGH}$, & 2 \\
\hline 502990.2, & 444284.22 , & 2.7574005 & 100.0 & 100.0, & 10.0, & 100000.0, & TILI_A, & Low, & 6 \\
\hline 502990.2, & 444384.22 & -187.2426 & 100.0, & 100.0, & 10.0, & 100000.0, & -99, & , & -99 \\
\hline 502990.2, & 444384.22 & -177.2426 & 100.0, & 100.0, & 10.0, & 100000.0, & -99, & , & -99 \\
\hline 502990.2 , & 444384.22 & -167.2426 & 100.0 & 100.0, & 10.0, & 100000.0, & -99, & , & -99 \\
\hline 502990.2, & 444384.22 & -77.2426 & 100.0 & 100.0, & 10.0, & 100000.0, & -99 & , & -99 \\
\hline 502990.2 , & 444384.22 & -67.2426 & 100.0 & 100.0, & 10.0, & 100000.0 & -99 & , & -99 \\
\hline 502990.2, & 444384.22 & -57.2426 & 100.0 & 100.0, & 10.0, & 100000.0, & -99, & , & -99 \\
\hline 502990.2 , & 444384.22 & -47.2426 & 100.0 & 100.0, & 10.0, & 100000.0, & CHLK, & $\mathrm{HIGH}$, & 2 \\
\hline 502990.2, & 444384.22 & -37.2426 , & 100.0 & 100.0, & 10.0, & 100000.0, & CHLK, & $\mathrm{HIGH}$, & 2 \\
\hline 502990.2 , & 444384.22 , & -27.2426 & 100.0, & 100.0, & 10.0, & 100000.0, & CHLK, & $\mathrm{HIGH}$, & 2 \\
\hline 502990.2 , & 444384.22 , & -17.2426, & 100.0, & 100.0, & 10.0, & 100000.0, & CHLK, & $\mathrm{HIGH}$, & 2 \\
\hline $502990.2 ，$ & 444384.22 & -7.2425995 , & 100.0, & 100.0, & 10.0, & 100000.0, & CHLK, & $\mathrm{HIGH}$, & 2 \\
\hline 502990.2 , & 444384.22 & 2.7574005 & 100.0, & 100.0, & 10.0, & 100000.0, & TILL_A, & LOW, & 6 \\
\hline 502990.2 , & 444484.22 & -187.2426 & 100.0 & 100.0, & 10.0, & 100000.0, & -99 & , & -99 \\
\hline
\end{tabular}

Figure 9: Example of the BlockModel export file, complete with the optional header rows 2, 3 and 4

\subsubsection{Stack of $2 D$ grids}

This export format is a generic format included to support members of the community who are more familiar with 2D grid formats commonly used within GIS applications. Despite advances in the use of 3D modeling software, many potential users lack access to sophisticated 3D applications, and many GSOs still perform a significant amount of spatial analysis and visualization using GIS software (Berg et al., 2011). This option generates one file per property, each file contains a 2D grid for the base of each stratigraphic unit or selected attribute category. 
When selecting this export option the user is not required to define a $\mathrm{Z}$ extent, the code will generate 2D grids from the lowest base to the top of the model. This option tends to generate smaller files than the other options and takes the least amount of time to complete.

To import into GIS software packages such as $\operatorname{ArcGIS}^{\mathrm{TM}}$, the individual surfaces can be extracted from this file and imported as an array of points, which can then be converted to a raster using the $\mathrm{Z}$ field and the cell size from the header information.

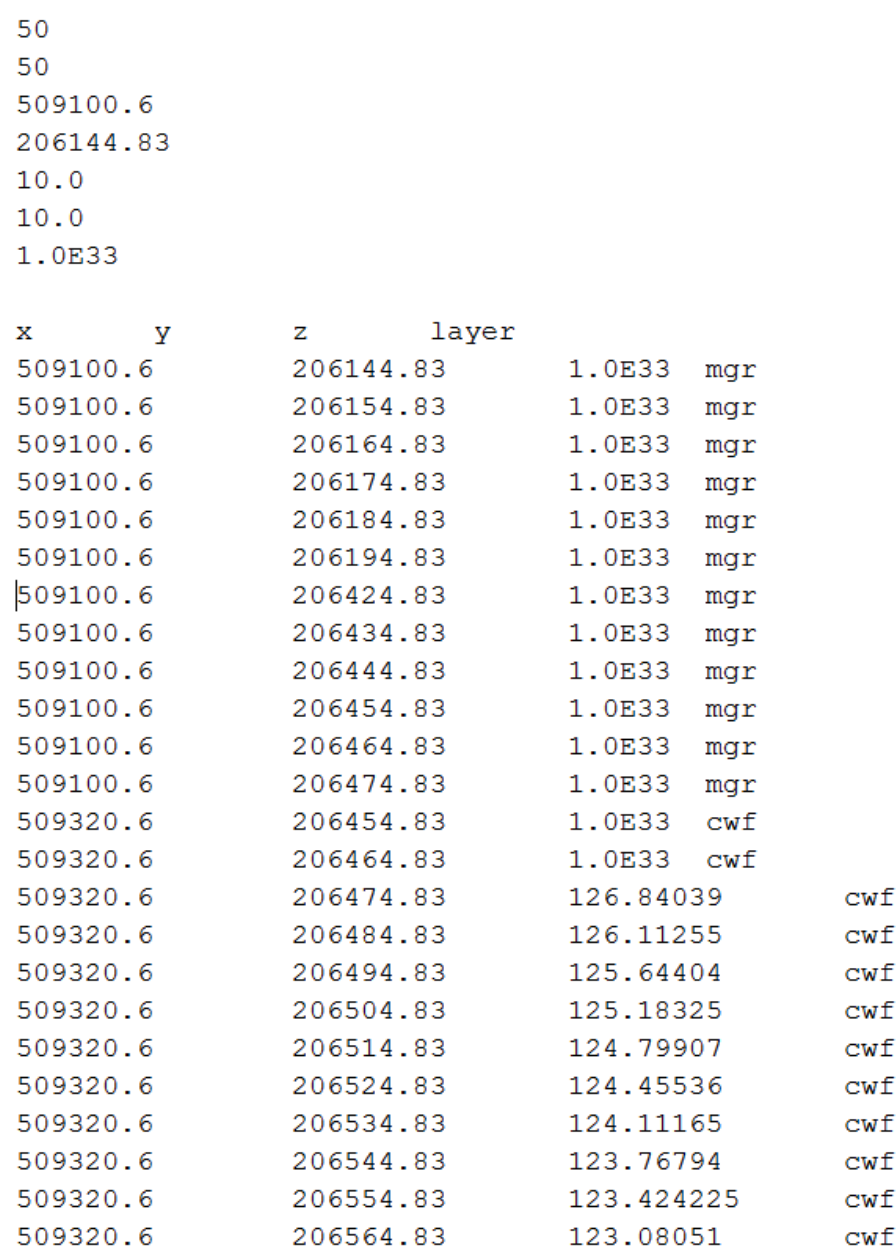

Figure 10: Stacked Grid example, where the selected property (layer) appears in the final column, if the property value identified in the final column does not exist in these cells the $\mathrm{z}$ coordinate contains noDataValue (1.0E33)

\section{Remaining Challenges}

During the development of SurfGrid, a number of issues and challenges were identified that could not be addressed immediately. These should be addressed in order to improve geological model reuse within process models.

i. To truly link the static geological knowledge contained within geological models to process models within model linkage frameworks, such as OpenMI or CSDMS (Peckham et al., 2013), requires expertise and significant effort from the IEM community. This will also require efforts by developers of the process models to re-factor their codes to incorporate static spatial data. 
ii. BGS has developed SurfGrid in-house as an extension to GSI3D and it is therefore not possible to release the tool in this form due to licensing restrictions. In order to meet the original objective of developing a solution that not only produces generic outputs but also uses geological modeled objects created in a range of software, the SurfGrid tool must be migrated away from a GSI3D plug-in implementation. The SurfGrid code has been developed with this migration in mind and therefore it should be relatively straightforward to produce a software independent version which could use 3D surfaces from a range of geological modeling tools. Rather than being released as stand-alone software, SurfGrid will be integrated with BGS' desktop Geoscientific Information System (GSIS) which is likely to become available as a free software download.

iii. A number of organizations have recently developed 3D geological object stores using relational database platforms (Gietzel et al., 2012; Wood, 2014), these provide a way to store and manage 3D model objects independent of proprietary geological modeling software. In the future, these databases could become the primary input source for SurfGrid and could potentially store the resultant gridded data, identify dependencies as well as appropriate metadata, identified as the key to maximizing the potential for data reuse (Giles, 2011; Hughes et al., 2013).

iv. To improve communication between geologists and process modelers, end users should be consulted to ensure that user interfaces are easy to use and the tools reflect the logical workflows between disciplines. 3D gridding tools can form a seamless step in an information flow of geological knowledge from 3D models into linked environmental models if they incorporate the capture of metadata and dependencies to support communication and feedback loops between disciplines (Figure 11). Improving intersystem links and feedback loops in this way would encourage a more iterative transfer of information between geological and process models as proposed by DAgnese et al. (1997) and others (Agada et al., 2014; Turner, 2006; Smith et al., 2012).

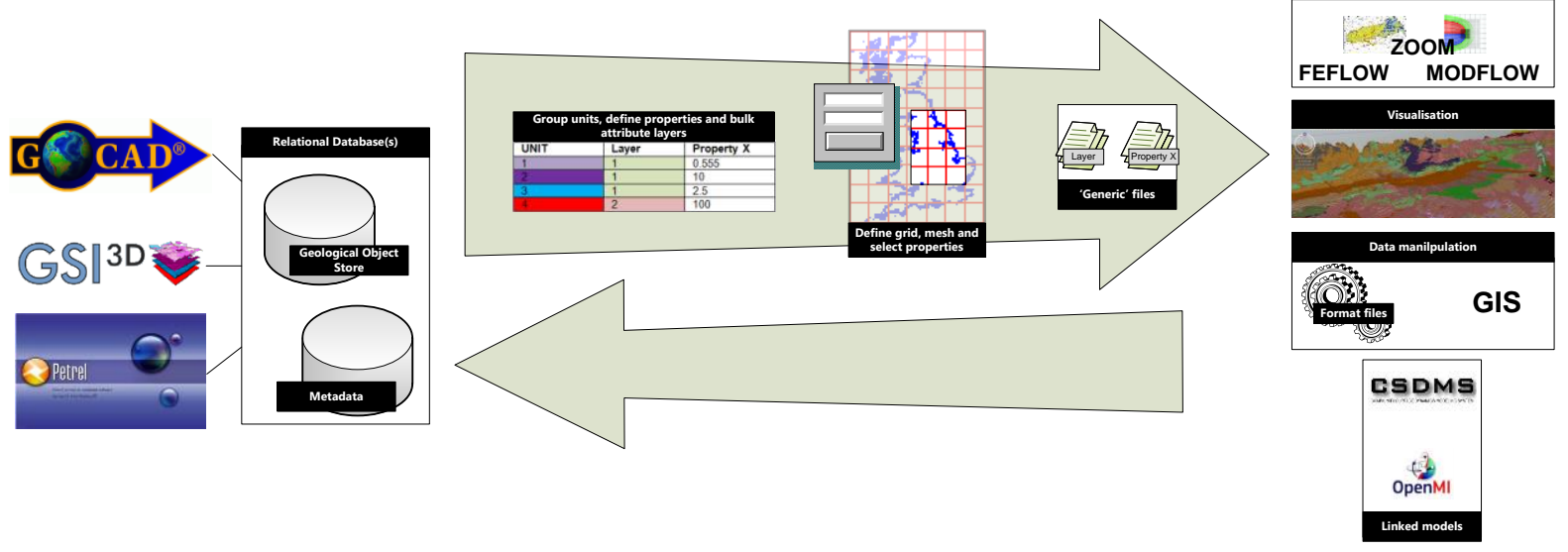

Figure 11: Proposed future workflow (Petrel is a mark of Schlumberger) 
v. The generation of multi-dimensional export grids requires significant amounts of computer memory and the current version of SurfGrid is limited by the amount of available computer memory. This can make model conversion and export slow, or impossible for very large models or for very high resolution exports. A disk-caching mechanism combined with a suitable binary grid data format such as NetCDF (Rew \& Davis, 1990) may alleviate this problem and will be investigated. Use of a binary grid format would also facilitate dynamic updating of the exported data because a small portion could be updated without the need to re-run the entire export; this could be a very significant efficiency gain on larger models at higher resolutions.

vi. The creation of 3D models which describe property-controlling subsurface structures that may or may not directly relate to lithostratigraphy, for example weathering zones or man-made structures, should also be considered. These may not be considered as structurally significant by a geologist but could have a huge impact upon the dynamic processes being modeled.

vii. Further analysis is required to address additional issues raised during the development of SurfGrid:

- Is a minimum thickness function required to support process models that require gridded layers to extend across the entire area of the model? Such functionality would ensure that very thin or laterally limited features, which have a significant impact on dynamic processes, remain present in SurfGrid exports.

- What support is required for semi-regular grid outputs? This is not regarded as an immediate concern, process modelers have suggested that nested grids could be produced by combining multiple exports of differing mesh sizes.

- How should alternatives to bulk attributing a volume with property values be incorporated into this solution?

\section{Conclusions}

The procedure and SurfGrid tool provide a flexible, user friendly way to generate multi-property exports from geological framework models. This is likely to lead to greater use of 3D modeled data in process models and a better representation of geological complexity within multidisciplinary process models and visualizations.

So far, the most popular SurfGrid export format has been the BlockModel option. It has been used to produce visualizations in the GeoVisionary software. This has helped to validate the outputs visually and identify spatiotemporal relationships when data from other sources are viewed together The Stack of 2D grids and CSV ASCII 3D grid formats are the most suitable formats for use in hydrogeological modeling software. Many groundwater flow modeling tools such as Visual MODFLOW support ESRI $2 \mathrm{D}$ grid format, used in the Stack of $2 \mathrm{D}$ grids export, making it the easiest option to load into 
groundwater models. The CSV ASCII 3D grid is closely related to the widely supported ESRI 2D grid format, it is clearly defined and human readable, making it relatively easy to write import functions against.

Geologists should consider how 3D geological models may be used and re-used by other disciplines. The creation of additional regional and catchment scale models would be very useful to process modelers.

Existing techniques for the transfer of geological structural information from 3D geological framework models into process models tend to support a very narrow range of software and require the creation of a new geological model for this purpose. The SurfGrid tool and procedure provide a generic, flexible solution that can be applied to both new and pre-existing 3D geological models. Additional efforts are also required to integrate this solution into logical IEM workflows, but this integration seems achievable in the relatively near future.

\section{Acknowledgements}

The authors thank various colleagues at the BGS, Jonathan Ford, Stephanie Bricker, Garry Baker, Martin Nayembil who have provided staff time and the freedom to carry out such research and development activities alongside day-to-day software and modeling duties.

Holger Kessler, Rachel Dearden and the BGS 3D model development team provided development time, technical advice and encouragement on all issues relating to GSI3D, the Geological Object Store and the SurfGrid tool.

Majdi Mansour and Jonathan Mackay provided information and images on the OpenMI linked model composition for the Thames catchment.

\section{References:}

Agada, S., F. Chen, S. Geiger, G. Toigulova, S. Agar, R. Shekhar, G. Benson et al., 2014. Numerical simulation of fluid-flow processes in a 3D high-resolution carbonate reservoir analogue. Petroleum Geoscience 20, no. 1 (2014): 125-142. DOI: 10.1144/petgeo2012-096

Aldiss, D.T.; Black, M.G.; Entwisle, D.C.; Page, D.P.; Terrington, R.L., 2012 Benefits of a 3D geological model for major tunnelling works : an example from Farringdon, east-central London, UK. Quarterly Journal of Engineering Geology and Hydrogeology, 45 (4). 405-414. DOI:10.1144/qjegh2011-066

Barlow, Paul M., and Arlen W. Harbaugh., 2006. USGS directions in MODFLOW development. Groundwater 44, no. 6 (2006): 771-774.

Berg, Richard C.; Mathers, Stephen J.; Kessler, Holger; Keefer, Donald A., eds., 2011. Synopsis of current three-dimensional geological mapping and modeling in Geological Survey organizations. Ilinois State Geological Survey Circular, 578. 104, pp. http://nora.nerc.ac.uk/17095/

Berlioux, Arnaud.,1994. Building models with GOCAD. Stanford Exploration Project (80): 588-607.

Blessent, Daniela, René Therrien, and Kerry MacQuarrie., 2009. Coupling geological and numerical models to simulate groundwater flow and contaminant transport in fractured media. Computers \& Geosciences 35, no. 9: 1897-1906. DOI: 10.1016/j.cageo.2008.12.008

D’Agnese, Frank A., Claudia C. Faunt, A. Keith Turner, and Mary C. Hill., 1997. Hydrogeologic evaluation and numerical simulation of the Death Valley Regional ground-water flow system, Nevada and California. U.S. Geological Survey Water Resources Investigations Report 96-4300, 124p. (Available from: http://pubs.er.usgs.gov/publication/wri964300)Fitch PG, Perraud JM, Cuddy, Seaton S, Bai Q and Hehir D., 
2012. The Hydrologists Workbench: more than a scientific workflow tool. Water Information Research and Development Alliance: Science Symposium Proceedings. Melbourne. 1-5 August 2012. Pp. 61-69.

Fogg, Graham E., Carle, Steven F., and Christopher Green, 2000, Connected-network paradigm for the alluvial aquifer system, Geological Society of America Special Papers 348: 25-42, DOI:10.1130/0-8137-23485.25Forward, Andrew, and Timothy C. Lethbridge., 2002. The relevance of software documentation, tools and technologies: a survey. In Proceedings of the 2002 Association for Computing Machinery (ACM) symposium on Document engineering, pp. 26-33.

Gietzel, Jan, Paul Gabriel, Helmut Schaeben, and Hai Ha Le., 2012. Use Models like Maps in a 3D SDI. In European Geosciences Union (EGU) General Assembly Conference Abstracts (Vol. 15, p. 242).

Giles, Jeremy RA., 2011. Geoscience metadata-No pain, no gain. Geological Society of America Special Papers 482: 29-33.

Giles, J. R., Hughes, A., Kessler, H., Watson, C., \& Peach, D., 2010. Data, and research for applications and models (DREAM): scoping study report. (OR/10/020) (Unpublished) http://nora.nerc.ac.uk/10745/

Hughes, A.G.; Harpham, Q.K.; Riddick, A.T.; Royse, K.R.; Singh, A., 2013 Meta-model : ensuring the widespread access to metadata and data for environmental models : scoping report. Nottingham, UK, British Geological Survey, 39pp. (OR/13/042) http://nora.nerc.ac.uk/504868/

Hughes, Andrew; Jackson, Chris; Mansour, Majdi; Bricker, Stephanie; Barkwith, Andrew; Williams, Ann; Abesser, Corinna; Wang, Lei., 2011. Integrated modelling within the Thames Basin: examples of BGS work. [Poster] In: Cities, catchments and coasts: applied geoscience for decision-making in London and the Thames Basin, London, UK, 13 May 2011. (Unpublished) http://nora.nerc.ac.uk/14267/

Hughes AG, Mansour MM, Robins NS., 2008. Evaluation of distributed recharge in an upland semi-arid karst system: the West Bank Mountain Aquifer. Hydrogeology Journal . DOI: 10.1007/s10040-008-0273-6.

Jackson, C.R., 2004. User's manual for the particle tracking model ZOOPT. British Geological Survey, 46pp. (IR/04/141) http://nora.nerc.ac.uk/12620/

Jackson CR, Spink AEF., 2004. User's Manual for the Groundwater Flow Model ZOOMQ3D. British Geological Survey Internal Report (IR/04/140) http://nora.nerc.ac.uk/11829/

King, Michael J., Paulo R. Ballin, Chakib Bennis, David E. Heath, Allan D. Hiebert, William McKenzie, JeanFrancois Rainaud, and Jana Schey., 2012. Reservoir modeling: From rescue to resqml. SPE Reservoir Evaluation \& Engineering 15, no. 02: 127-138. DOI http://dx.doi.org/10.2118/135280-PA

Kessler, H., Mathers, S.J. \& H.-G. Sobisch. 2009. The capture and dissemination of integrated 3D geospatial knowledge at the British Geological Survey using GSI3D software and methodology. Computers \& Geosciences, 35, 1311-1321. http://dx.doi.org/10.1016/j.cageo.2008.04.005; http://nora.nerc.ac.uk/7207/1/Kessler_CG_GSI3D_article_final.pdf

Kessler, Holger; Mathers, Stephen. 2006 The past, present and future of 3D geology in BGS. Journal Open University Geological Society, 27 (2). 13-15.

Labourdette, Richard, Joann Hegre, Patrice Imbert, and Enzo Insalaco., 2008. Reservoir-scale 3D sedimentary modelling: approaches to integrate sedimentology into a reservoir characterization workflow. Geological Society, London, Special Publications 309, no. 1: 75-85.

Laniak, Gerard F.; Olchin, Gabriel; Goodall, Jonathan; Voinov, Alexey; Hill, Mary; Glynn, Pierre; Whelan, Gene; Geller, Gary; Quinn, Nigel; Blind, Michiel; Peckham, Scott; Reaney, Sim; Gaber, Noha; Kennedy, Robert; Hughes, Andrew., 2013. Integrated environmental modeling : a vision and roadmap for the future. Environmental Modelling \& Software, 39. 3-23. 10.1016/j.envsoft.2012.09.006 http://nora.nerc.ac.uk/20718/

Mackay, J.; Mansour, M.; Abesser, C.; Jackson, C.; Williams, A.; Hughes, A.; Pachocka, M.; Wang, L.; Kingdon, A., 2013 Integrated surface and groundwater modelling in the Thames Basin, UK using the Open Modelling Interface. [Speech] In: EGU General Assembly 2013, Vienna, Austria, 7-12 April 2013. http://nora.nerc.ac.uk/501461/

Mansour M.M., Hughes A., O Dochartaigh B., Graham M., 2008. Representation of Urban Recharge Processes in the Distributed Recharge Model (ZOODRM) of the Glasgow urban area, Scotland. In: MODFLOW and More 2008: Ground Water and Public Policy, Golden, IGWMC, Colorado, USA, 19th-21st May 2008. http://nora.nerc.ac.uk/9795/

Mansour, Majdi; Mackay, Jonathan; Abesser, Corinna; Williams, Ann; Wang, Lei; Bricker, Stephanie; Jackson, Christopher., 2013. Integrated Environmental Modeling applied at the basin scale: linking different types of models using the OpenMI standard to improve simulation of groundwater processes in the Thames Basin, UK. In: MODFLOW and More: Translating Science into Practice, IGWMC, Golden, Colorado, USA, 2-5 June 2013. (Unpublished) http://nora.nerc.ac.uk/501789/

Manzocchi, T., C. Childs, and J. J. Walsh., 2010. Faults and fault properties in hydrocarbon flow models. Geofluids 10, no. 1-2: 94-113. DOI: 10.1111/j.1468-8123.2010.00283.x

Moore, Roger; Hughes, Andrew; Gaber, Noha; Geller, Gary; Glynn, Pierre; Laniak, Gerry; Voinov, Alexey; Whelan, Gene., 2012. International Summit on Integrated Environmental Modeling. US Environmental Protection Agency, 62pp. (OR/12/087) - http://nora.nerc.ac.uk/21007/ 
Mathers, S. J., Burke, H. F., Terrington, R. L., Thorpe, S., Dearden, R. A., Williamson, J. P., \& Ford, J. R., 2014. A geological model of London and the Thames Valley, southeast England. Proceedings of the Geologists' Association.

McRae, B. H., and V. B. Shah., 2009. Circuitscape user guide. University of California, Santa Barbara http://circuitscape. org

Napier, Bruce., 2011. GeoVisionary: virtual fieldwork for real geologists. V1 Magazine. http://nora.nerc.ac.uk/13558/

Ormsby, T., Napoleon, E., Burke, R., Groessl C., and L. Bowden, 2010, Getting to Know ArcGIS Desktop, Second Edition, Updated for ArcGIS 10, ESRI Press, 604 p. ISBN: 9781589482609

Peckham, Scott D., Eric WH Hutton, and Boyana Norris., 2013. A component-based approach to integrated modeling in the geosciences: The design of CSDMS. Computers \& Geosciences 53: 3-12.

Rew, Russ, and Glenn Davis., 1990. NetCDF: an interface for scientific data access. Computer Graphics and Applications, IEEE 10, no. 4: 76-82.

Ross, M., Aitssi, L., Martel, R., \& Parent. M., 2005. From geological to groundwater flow models: An example of inter-operability for semi-regular grids. Geological Society of America Annual Meeting, Geological Survey of Canada, Salt Lake City, UT, USA, Open File 5048: 67-70.

Royse, Katherine R., 2010. Combining numerical and cognitive 3D modelling approaches in order to determine the structure of the Chalk in the London Basin. Computers \& Geosciences 36.4: 500-511.

Royse, K. R., H. K. Rutter, and D. C. Entwisle., 2009. Property attribution of 3D geological models in the Thames Gateway, London: new ways of visualising geoscientific information. Bulletin of Engineering Geology and the Environment 68.1: 1-16.

Smirnoff, A., Blouin, M., Paradis, S.J., Ross, M., 2011. Transferring geological properties from 3D geomodels to groundwater models with GOFEFLOW. Geohydro2011, Proceedings of the Joint meeting of the Canadian Quaternary Association and the Canadian Chapter of the International Association of Hydrologeologists, Quebec City, August 28-31.

Smith, Martin, David Lawrence, David McInroy, Alison Monaghan, Mike Edwards, Mark Naylor, Jon Ford, and Stephanie Bricker., 2012. Defining the store: geological interpretation and storage modelling. 37-67.

Stafleu, J., Sobisch, H. G., Maljers, D., Hummelman, J., Damrink, R. M., \& Gunnink, J.L., 2013. Visualization and dissemination of 3D geological property models of the Netherlands. In European Geosciences Union (EGU) General Assembly Conference Abstracts. (Vol. 15, P.8770).

Trefry, Mike G., and Chris Muffels., 2007. FEFLOW: A Finite-Element Ground Water Flow and Transport Modeling Tool. Groundwater 45.5: 525-528. doi:10.1111/j.1745-6584.2007.00358.x

Turner, A. Keith., 2006. Challenges and trends for geological modelling and visualisation. Bulletin of Engineering Geology and the Environment 65, no. 2: 109-127.

Whiteman, M. I., K. J. Seymour, J. J. Van Wonderen, C. H. Maginness, P. J. Hulme, M. W. Grout, and R. P. Farrell., 2012. Start, development and status of the regulator-led national groundwater resources modelling programme in England and Wales. Geological Society, London, Special Publications 364, no. 1: 19-37.

Wood, B., Howcroft, J., Mathers, S., Nayembil, M., Dearden, R. and H. Kessler, 2014, A System for Management of 3D Geological Models at the British Geological Survey, Geological Society of America Abstracts with Programs, 46 (6): 685 (Available from: https://gsa.confex.com/gsa/2014AM/webprogram/Paper244660.html )

\section{Web references}

Maptek (2013). "Maptek Vulcan 3D Modelling and Mine Planning Software" [Brochure]. http://www.maptek.com/pdf/vulcan/Maptek_Vulcan_overview_brochure.pdf. Last accessed September 3rd 2014

Schlumberger (2014) "Petrel Geology and Modeling. From 1D petroleum systems through structural modelling, to reservoir characterization across the E\&P lifecycle" [Brochure]. http://www.software.slb.com/Lists/SalesandMarketingDocuments/Attachments/421/petrel_geology_modelin g.pdf. Last accessed September 3rd 2014

OpenMI Association, 2010. OpenMI Standard 2 Specification for the OpenMI (Version 2.0). Part of the OpenMI Document Series. World Wide Web address: http://www.openmi.org. 